\title{
Study on the Protection of Intangible Cultural Heritage and the Utilization of Rural Tourism
}

\author{
-Taking Yangliuqing Town, Xiqing District, Tianjin as an Example
}

\author{
Zhida Wang, Hongmei Gao*, Jingjing Bing \\ Department of Economic Management \\ Tianjin Agriculture University \\ Tianjin, China
}

\begin{abstract}
The report of the 19th National Congress of the Communist Party of China pointed out that without a high degree of cultural self-confidence and without the prosperity of culture, there would be no great rejuvenation of the Chinese nation. The tourism utilization of intangible cultural heritage has exerted the advantages of both tourism industry and cultural industry, which helps to establish cultural self-confidence and cultural identity. Based on this, this study takes Tianjin Yangliuqing Town as the research object, which is to solve the problem that its rich regional culture and many cultural relics cannot be rationally utilized. Using the field investigation method and household visits, it is concluded that only the intangible cultural heritage can be properly protected and the intangible cultural heritage unique to Yangliuqing Town can be excavated in order to promote the development of tourism, industry and inheritance. Provide countermeasures for tourism development and utilization.
\end{abstract}

Keywords-intangible cultural heritage protection; rural tourism; use; Yangliuqing Town

\section{INTRODUCTION}

At present, China is in the transitional stage from tourism to tourism and leisure tourism. The requirements of consumers can be summarized as consumption upgrading and multidimensional coexistence. Upgrades and supply-side reforms have therefore become the focus of the tourism industry. Originating from this, this article takes Yangliuqing Town, Xiqing District, Tianjin as the entry point, and pays attention to the intangible culture, the courtyard culture, the rushing culture, the wooden board painting, the red culture and many other intangible cultural heritages behind it. Promote the support of social development in the context of space and time in the context of industrialization, urbanization, and informationization. At the same time, the tourism utilization of intangible cultural heritage echoes the national strategy of improving and improving the tourism industry, adapts to the new changes in consumption trends, and is also an inevitable requirement for tourism to play the role of the strategic pillar industry of the national economy.

\section{Non-LEGACY PROTECTION AND DEVELOPMENT AND UTILIZATION OF RURAL TOURISM}

China's tourism development and intangible cultural heritage (hereinafter referred to as non-legacy) complement each other in practice. The core competitiveness of tourism destinations comes from the difference and regionality of tourism destinations, while the non-legacy preserves the regionality of tourism destinations. And the unique quality has become an important factor to attract tourists[1]. This paper believes that as a folk culture, it has obvious tension and resilience, can change in inheritance, adapt to change, and has the color of official ideology. There is also a style of non-government behavior; it can be extended and passed down, and it can be absorbed and created. Therefore, the protection of non-legacy is fundamentally to return to daily life, return to the people, return to the countryside, and it is the soil for survival and continuation[2]. As a researcher and practitioner of tourism phenomena, we are also a follower and beneficiary of nonlegacy. For a long time, there may be an illusion that as long as the concept is appropriate and the method is right, it seems that one can always find a kind. Transforming traditional nonheritage into a practical technology for modern tourism projects that tourists like to see and are willing to pay for, and implement it as a type of tourism product Folklore tourism, traditional tourism, etc. In fact, we probably have not yet realized and respected the essence of such heritage. Technical self-confidence may make us forget to think about some ground-breaking problems. Then we can't happen on scale Dislocation, think that it can be transformed, promoted and expanded from the level of "social" according to the modern economic concept and its organizational means.[3]. Really want to make good use of this kind of heritage to serve the tourism industry, but also in terms of perspective only by considering the two dimensions of scale can we effectively carry on and carry forward it 


\section{OVERVIEW OF THE DEVELOPMENT OF YANGLIUQING TOWN AND ITS CURRENT SITUATION}

\section{A. Abbreviations and Acronyms}

Yangliuqing is called Liukou in ancient times, and the old ones belonged to Wuqing and Jinghai counties[4]. During the Yuan, Ming and Qing Dynasties, with the increase in demand for materials, the towns and cities along the canal roads of Nanliangbeiyun were gathered together, and the trade was more prosperous. Yangliuqing Town It also developed. Qingzheng Zhengjiu (1731), Tianjin Government is attached to Tianjin County, Yangliuqingyi is under the jurisdiction of Tianjin, and is a major town of Jinxi[5]. Today, Yangliuqing Town belongs to Tianjin Xiqing District, which is Xiqing. The resident of the district government is also the economic and cultural center of Xiqing District. It covers an area of 64 square kilometers, with a town area of 15 square kilometers and a total population of 140,000 . It is the largest township in Tianjin and the Bohai Economic Zone, and the largest manmade in Tianjin. Satellite city, and one of the eight characteristic tourist service towns.

\section{B. Status of cultural resources}

Yangliuqing Town is an ancient town with a thousand years of historical civilization (Table I).The characteristic ancient buildings of Yangliuqing Town and its unique folk culture (Shijia Courtyard, New Year Pictures, New Year Painting Hall) are important historical and cultural tourism resources of Tianjin, especially the national non-legacy projects represented by Yangliuqing wooden board paintings. It is also known throughout the country. Yangliuqing folk culture is very rich, and the theater, archway and Wenchang Pavilion are known as Yangliuqing Sanzongbao. Located in the center of the town, the Shijia Courtyard in the late Qing Dynasty is known as the "first residential house in North China". Together with the New Year Gallery, Ming and Qing Street and the South Canal, it forms the folk culture tourism base of Yangliuqing Town.

TABLE I. LIST OF TIANJIN HISTORICAL AND CULTURAL TOWNS

\begin{tabular}{|c|c|c|c|}
\hline Numbering & Name & Region & Level \\
\hline 1 & Yangliuqing Town & Xiqing District & National level \\
\hline 2 & Duliu Town & Jinghai County & Municipal level \\
\hline 3 & Gezhen Town & Jinnan District & Municipal level \\
\hline
\end{tabular}

1) Water transport culture

Yangliuqing Town is flourishing due to water. Water has cast the bones and spirits of the ancient town. The influence of water transport on cultural customs and water transport has certain influence on the development of local people's sentiments and social culture. "Tianjin Yangliuqing Xiaozhi" records that the number of boats Huge, a large number of soils are sold at the docks along the way. A large number of northsouth commercial goods are sold and sold along the riverbank. The commercial market is booming. With the development of the commercial economy, a large number of North-South merchants have flowed or settled here, making local dialects gradually. It combines the characteristics of different local languages and reflects the rich folk language and customs of Yangliuqing[6]. In the thirteenth year of Ming Yongle, the
Beijing-Hangzhou Grand Canal runs through, and the Yangliuqing Town has risen. At this time, Yang Liuqing has developed from the military base of the Jin and Yuan Dynasties. An important commercial town in the north during the Ming and Qing Dynasties[7].

\section{2) Courtyard Culture}

The Shijia Courtyard was built in 1875 and was the former residence of Shi Yuanshi, one of the eight major figures in Tianjin in the Qing Dynasty. It covers an area of 7,200 square meters, including a construction area of over 2,900 square meters. The whole consists of 12 four-piece courtyards distributed on both sides of the 60-meter long ramp. Regardless of the overall pattern, architectural style, or artistic decoration, it reflects the cultural legacy of the late Qing Dynasty and the early Republic of China and the folk customs at that time. Anjia Courtyard was built during the Tongzhi Period of the Qing Dynasty. Covering an area of $200 \mathrm{mu}$, it consists of three courtyards. It is the tallest ancient building in Yangliuqing Town. It is also the largest ancient building in Yangliuqing Town. It is a typical northern residence. The Anshi Temple was built in 1720 and has a history of 285 years. The An's Ancestral Hall is located south facing south and consists of two entrance courtyards with a building area of 630 square meters. Both are bluestone high-rises, and the bricks are sewn together, which is a typical Qing Dynasty architectural style.

\section{3) New Year painting culture}

Yang Liuqing is one of the hometowns of China's four woodcut New Year pictures.The Yangliu Qingmu New Year painting is a wonderful work in the history of Chinese folk art. It has a history of more than 380 years and is an outstanding representative of Chinese folk art.It has four unique advantages: obvious agglomeration effect, reasonable industrial structure, obvious characteristic advantages and talent attraction.Yangliuqing Town has built a New Year painting museum, a folk culture museum, Ming and Qing Street and other cultural exchange spaces for the New Year painting, which laid a solid foundation for the industrialization of the New Year painting.Among the more than a thousand businessmen, there are nearly one hundred studios of new year paintings. About 2,000 people are engaged in the design, creation, production and sales of Yangliuqing paintings.

\section{4) Catch the camp culture}

"Catch up with the brigade" is a feat of the people of Tianjin. This is also a miracle in the history of modern Chinese business. From "Yangying", which has been going west from Yangliuqing, there are 153 stations, a total of 8171 miles, and it takes about half a year to reach Dihua. Bring it to Xinjiang. Advanced industries, handicrafts, traditional techniques, such as abacus, papermaking, metallurgical technology, crop planting, etc., have promoted the prosperity of all walks of life in Xinjiang, and introduced advanced concepts of service, business and transportation into Xinjiang. According to historical records "Catch the big camp" successfully made 15,000 Yangliuqing people successfully immigrated to Xinjiang, accounting for about one-fifth of the total population of Yang Liuqing at that time. It changed the political, economic and cultural features of Xinjiang and affected China with a small town. One-sixth of the land has 
been in existence for decades, which is indeed rare in Chinese history[8].

\section{5) Red culture}

Xiqing District currently has four red tourist destinations.Among them, the former site of Pingjin Campaign Front Line is located at No. 2, East Wangyao Street, Yangliuqing Town. It is now an exhibition hall and is a Tianjin-level cultural relics protection unit. The 12th and 9th Anti-Japanese National Salvation Movement Memorial Hall is located in Wanglanzhuang Village and is the only one in the country. The 12th and 9th Movement Memorial Hall is now a municipal-level cultural relics protection unit; the Xiqing Martyrs Cemetery is located on the bank of the Yangliu Qingnan Canal. It has a martyrs memorial and a monument, which vividly reproduces the feat of the Chinese and British people in the Tianjin campaign; China's anti-corruption first The large-scale exhibition hall is now the Tianjin Anticorruption Education Base.

\section{INTANGIBLE PROTECTION AND THE CHALLENGES OF RURAL TOURISM UTILIZATION}

\section{A. Non-genetic inheritance}

Taking Yangliuqing Town's New Year's painting as an example, it shows a natural development trend in production, and there are a large number of small-scale annual painting production and sales activities, and there is a flood of market driven by the market. On the one hand, due to production capacity constraints, the products of these small workshops lack innovation, and the works are similar, which reduces the quality of young Yangliu paintings. On the other hand, in order to maximize the interests, small workshops often only choose products with low prices for production. Even with false and shoddy, this has a huge impact on the production and sales of high-level new year paintings, which is detrimental to the healthy development of young willow paintings.

\section{B. The cultural industry structure is not reasonable}

First of all, although the industrial structure of Xiqing District has undergone tremendous changes since the reform and opening up, the tertiary industry has not received much attention and has been in a state of slow growth for a long time.As an important part of the third industry in Xiqing District, the cultural industry has always been a low proportion of the GDP of the whole region, and is far lower than the average level of other districts and counties. Moreover, in the overall industrial layout of Xiqing District, the cultural industry has not received enough attention. The
"Tianqing District Master Plan (2008-2020)" and some special plans have not adequately and fully analyzed the cultural industry, and there are still some inadequacies in its understanding, and the corresponding development strategies are relatively few. In addition, the understanding of the connotation of cultural functions is more unilateral, and there is a wrong tendency to equate cultural industries with tourism, leading to more attention to tourism-related industries such as "tour, purchase, entertainment, food, housing, and travel", while ignoring culture. The related research and development, production and promotion of products have caused the current development trend of the cultural industry in Xiqing District.

\section{The tourism strength is not strong and lacks integration}

In addition, there are many problems in the internal development of Xiqing District. The propaganda of the courtyard culture and the canal culture has not been publicized The current development and utilization is obviously lagging behind, and it still stays in the extensive management mode of ticket management (Fig.1).The folk culture with Yang Liuqing as the core, as well as the cultural resources of agriculture, red, martial arts, religion and other topics together constitute the rich cultural resources of Xiqing District. However, except for Yangliuqing Town, the scale of other scenic spots is very limited. In addition, the layout is relatively scattered, and the transportation links between them are not close enough, which leads to the isolation and development of each scenic spot, and it is impossible to form a complete industrial chain with agglomeration effect. Under the development model, resources of different themes are difficult to integrate, and it is not only difficult to coordinate the development and form a synergy. If this kind of individual situation continues, there will be problems such as redundant construction of infrastructure and vicious competition between scenic spots. Great waste of nonlegacy cultural resources in Xiqing District (Table II).

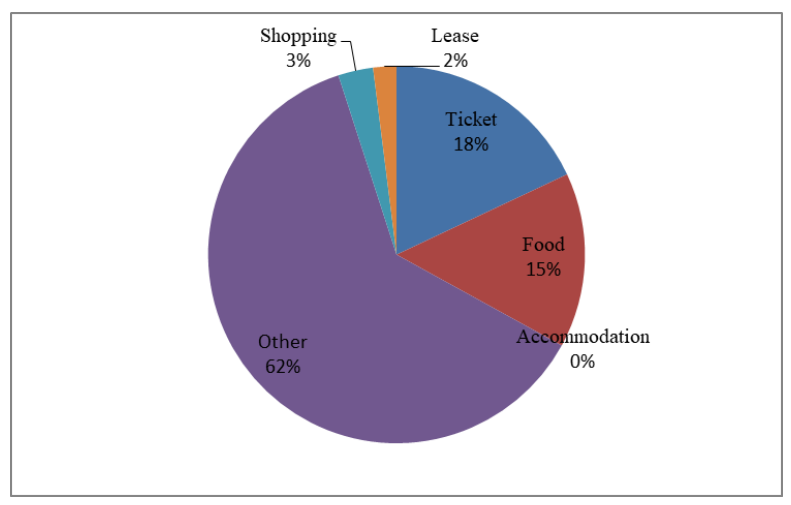

Fig.1. Tourism income of Yangliuqing Town in 2018

TABLE II. VISITOR STATISTICS OF YANGLIUQING TOWN SCENIC SPOT IN 2018

\begin{tabular}{|c|c|c|c|c|c|}
\hline Name & Travel agency & Individual & The same period of 2017 & Total number in 2018 & Year on year \\
\hline Shijia courtyard & 7606 & 377254 & 330000 & 384860 & $16.62 \%$ \\
\hline Anjia courtyard & 0 & 23100 & 40700 & 23100 & $-43.24 \%$ \\
\hline Ruyi street & 15000 & 507700 & 3359000 & 522700 & $-84.44 \%$ \\
\hline $\begin{array}{l}\text { The former site of the tianjin frontline } \\
\text { command of the pingjin campaign }\end{array}$ & 0 & 5557 & 6968 & 5557 & $-20.25 \%$ \\
\hline Yang liuqing manor & 40000 & 493900 & 772300 & 533900 & $-3087 \%$ \\
\hline
\end{tabular}


sustainable development of the scenic spot. Yangliuqing Town has historical culture and natural scenery. In order to rely on the integration of planning and restoration, Yuhe Scenic Area, Shijia Courtyard, Anjia Courtyard and Ruyi Street and other cultural tourism resources, to create a good cultural heritage pilot for the whole town unit. Inherit and promote the New Year pictures, paper-cut, kites, brick carving, etc. Material cultural heritage, increase the protection and publicity of the excellent cultural heritage of Yangliuqing Town, and work together to improve the intrinsic value of Yangliuqing's intangible cultural heritage.

\section{CONCLUSION}

It is very urgent and necessary for the protection of the current domestic awakening. Based on this, this paper is based on the research of many scholars, through the close integration of the background of non-legacy culture and the actual needs of the development of China's rural cultural tourism industry, to find a way suitable for China's development of rural heritage and excellent cultural functions. This research is mainly focused on, first, to vigorously explore and develop the non-legacy culture of the village, "not only must stand out, but also the spring of the park." At the same time, we developed distinctive cultural products and projects for the needs of tourists. Secondly, we found that non-legacy cultures have contributed to the deepening of social and economic development. Third, the research proposes to broaden the development direction, create a combination of farming and tourism, and coordinate Advise, coordinate development, upgrade industrial structure, carry out green development, and protect historical and cultural protection strategies.

\section{ACKNOWLEDGMENT}

This study is grateful to Tianjin Wuqing District Science and Technology Development Project (WQKJ201803) for funding.

\section{REFERENCES}

[1] Tao Weibing. The changes, inheritance and innovation path of rural folk culture in the new era [J]. Learning and Practice, pp. 133-140, January 2018. (In Chinese)

[2] Cui Wei. Protection of Intangible Cultural Heritage under the Vision of Rural Revitalization [J]. Agricultural Economy, pp. 45-46, June 2019. (In Chinese)

[3] Zhu Dandan, Zhang Yuxi. A review of the impact of tourism on the inheritance of rural culture [J]. Journal of Beijing Forestry University (Social Science Edition), pp. 58-62, February 2008. (In Chinese)

[4] Lai Xinxia, Guo Fengqi. Tianjin Tongzhi: Old Zhidian School Roll [M] Tianjin: Nankai University Press, 1999. (In Chinese)

[5] (Qing) Tao Baolian. Xin Mao Shi Xing Ji: Volume I [M]. Qing Guangxu twenty-three years of raising trees in the mountain house. (In Chinese)

[6] (Qing) Wang Lutai.Ji Fu An Lan Zhi: Yuhe [M]. Qing Dynasty Wuying Temple Juzhen Edition series books. (In Chinese)

[7] (Qing) Zhang Wei. Jinmen Miscellaneous [M]. Tianjin: Tianjin Ancient Books Publishing House, 1986. (In Chinese)

[8] Wang Yabin.Analysis of the History of Yang Liuqing's "Catch the Camp"[J]. Journal of Taian Education College, Zhu Zong, vol. 13, pp. 48-49, April 2009. (In Chinese) in ecological protection, create a good tourism environment, rationally develop tourism resources, and promote the 